\title{
LIMIAR DE PRECIPITAÇÃO COM POTENCIAL DE GERAR DESLIZAMENTOS NOS COMPLEXOS DE RISCO EM UMA ZONA URBANA
}

\author{
PRECIPITATION THRESHOLD WITH POTENTIAL TO \\ GENERATE LANDSLIDES AT RISK COMPLEXES IN AN \\ URBAN ZONE
}

David de Lima Santos, Carlos Ruberto Fragoso Jr., Vladimir Caramori Borges de Souza

Universidade Federal de Alagoas, Maceió, AL, Brasil. E-mail: david.as@hotmail.com; crubertofj@hotmail.com; vcaramori@yahoo.com

Como citar: SANTOS, D. L.; FRAGOSO JR., C. R.; SOUZA, V. C. B. Limiar de precipitação com potencial de gerar deslizamentos nos complexos de risco em uma zona urbana. Revista de Gestão de Água da América Latina, v. 16, e12, 2019. https://dx.doi.org/10.21168/rega.v16e12.

\begin{abstract}
RESUMO: Os desastres naturais de deslizamentos de terra e inundações são eventos que podem causar catástrofes de grandes proporções, levando a altos impactos socioeconômicos e ambientais em todo mundo. No Brasil, em estados como o Rio de Janeiro, sirenes para emissão de alertas são acionadas todo ano, avisando a população sobre a possibilidade da ocorrência de eventos de deslizamentos, enxurradas, inundações, causados por fortes chuvas. Os eventos de deslizamentos de terra geralmente são consequências de chuvas intensas, independentemente do local de ocorrência. 0 objetivo deste trabalho foi estabelecer limiares de chuvas para ás áreas de riscos de Maceió através das avaliações das ocorrências registradas de deslizamentos de terra e das chuvas registradas. 0 município de Maceió é o mais populoso do estado de Alagoas e apresenta cerca de 575 áreas de risco, divididas em complexos. A Defesa Civil deste município registra as ocorrências de deslizamentos de terra causadas por diversos fatores, entre eles as chuvas intensas. Foi evidenciado neste trabalho, que não se pode aplicar uma regra geral para a determinação dos limiares, devido as características particulares de cada zona de risco. Os limiares sugeridos para a cidade de Maceió foram de $40 \mathrm{~mm}$ para chuvas diárias, com durações mínimas menores ou iguais a $5 \mathrm{~h}$, e o acumulado de $100 \mathrm{~mm}$ em 2 dias de chuva.
\end{abstract}

Palavras-chave: Desastres naturais, áreas de risco, deslizamentos de terra, limiar de precipitação.

ABSTRACT: Natural disasters of landslides and flooding are events that can cause major disasters, leading to high socioeconomic and environmental impacts worldwide. In Brazil, in states such as Rio de Janeiro, sirens for warning alerts are triggered every year, warning the population about the possibility of events of landslides, flushes, floods, caused by heavy rains. Landslide events are usually a consequence of heavy rainfall, regardless of where they occur. The objective of this work was to establish rainfall thresholds for the risk areas of Maceió by assessing recorded occurrences of landslides and recorded rainfall. The municipality of Maceió is the most populous in the state of Alagoas and has about 575 risk areas, divided into risk complexes. The Civil Defense of this municipality records the occurrences of landslides caused by several factors, including heavy rains. It was shown in this paper that a general rule for threshold determination cannot be applied due to the particular characteristics of each risk zone. The suggested thresholds for the city of Maceió were $40 \mathrm{~mm}$ for daily rainfall, with minimum durations less than or equal to $5 \mathrm{~h}$, and the cumulative $100 \mathrm{~mm}$ in 2 rainy days.

Keywords: Natural disasters, areas of risk, landslides, precipitation threshold.

\section{INTRODUÇÃO}

As precipitações de grande intensidade podem gerar catástrofes quando combinadas com regiões suscetíveis a movimentos terra ou alagamentos e inundações. Áreas como encostas e margens de rios, são mais frágeis no ponto de vista da influência das precipitações e, por este motivo, são regiões consideradas de risco (Molina et al., 2015). 
Em um período de 10 anos apurados entre 2005 e 2014, o valor gasto com desastres naturais no mundo atingiu o valor aproximado de 1,4 trilhões de dólares. Os deslizamentos de terra estão entre os desastres frequentes em todo o mundo, com ocorrências recorrentes em diversas regiões do Brasil (UNISDR, 2015, 2018; Brasil, 2013, 2018).

No Brasil, a administração municipal é responsável por organizar a ocupação do solo, cabendo a ela a liberação e a fiscalização de construções e ocupações nos seus limites territoriais. A falta de fiscalização e a ocupação de áreas de risco sem (ou com baixo nível de) planejamento potencializam a ocorrência de deslizamentos de terra ocasionados por chuvas intensas, frequentemente não observando os limites e restrições estabelecidos na Lei de Parcelamento, Uso e Ocupação do Solo (Brasil, 1979) e no Código Florestal Brasileiro (Brasil, 2012b) e demais documentos correlatos.

A defesa civil (DC), por sua vez, é o órgão municipal responsável pelo acompanhamento e atuação nas áreas de risco de deslizamentos nos municípios e também efetua os registros das ocorrências nessas áreas (Brasil, 2012a).

As áreas de risco de deslizamentos (conforme mostrado na Figura 1) são caracterizadas como críticas devido a presença de encostas ocupadas de forma desordenada e com construções mal planejadas e executadas de forma precária, tornando-as com potencial de deslizamento durante a ocorrência de eventos chuvosos. Um bom exemplo é a execução de cortes e aterros em encostas sem observância dos padrões normativos e dos limites legais de uso e ocupação do solo (Parizzi et al., 2010).

A literatura mostra que a maior influência na ocorrência de deslizamentos está relacionada às altas intensidades de precipitação, independentemente de a precipitação anual estar próxima ou não da média esperada (Huang et al., 2015). Vários estudos apresentaram uma correlação positiva entre estas variáveis, tentando identificar limiares de precipitação que geram deslizamentos, destacando a peculiaridade da regionalidade desta informação (Tatizana et al., 1987a, 1987b; Castro, 2006; Tominaga et al., 2009; Santoro et al., 2010; Parizzi et al., 2010; Michel, 2013; Michel et al., 2014, 2015; Martins, 2014; Molina et al., 2015; Mendes et al., 2015; Kobiyama et al., 2015; Ribeiro Neto et al., 2016; Zahiri et al., 2016).

Estudos de limiares de precipitação que geram os deslizamentos de terra, apontam a intensidade da chuva (Huang et al., 2015) e o acumulado de chuvas em um período de tempo de até 4 dias (Tatizana et al., 1987a, 1987b; Molina et al., 2015) como os principais fatores pluviométricos que desencadeiam os movimentos de massa e devem ser avaliados regionalmente para definir o limiar. Esses estudos, são aplicados em áreas de características semelhantes e homogêneas, sem grandes variações. No entanto, como os eventos de deslizamentos de terra são corriqueiros e acontecem em todo mundo, é importante a avaliação regional, considerando-se as diferenças de padrões de uso e ocupação do solo, das feições do relevo e da drenagem, das características da precipitação, dentre outros aspectos.

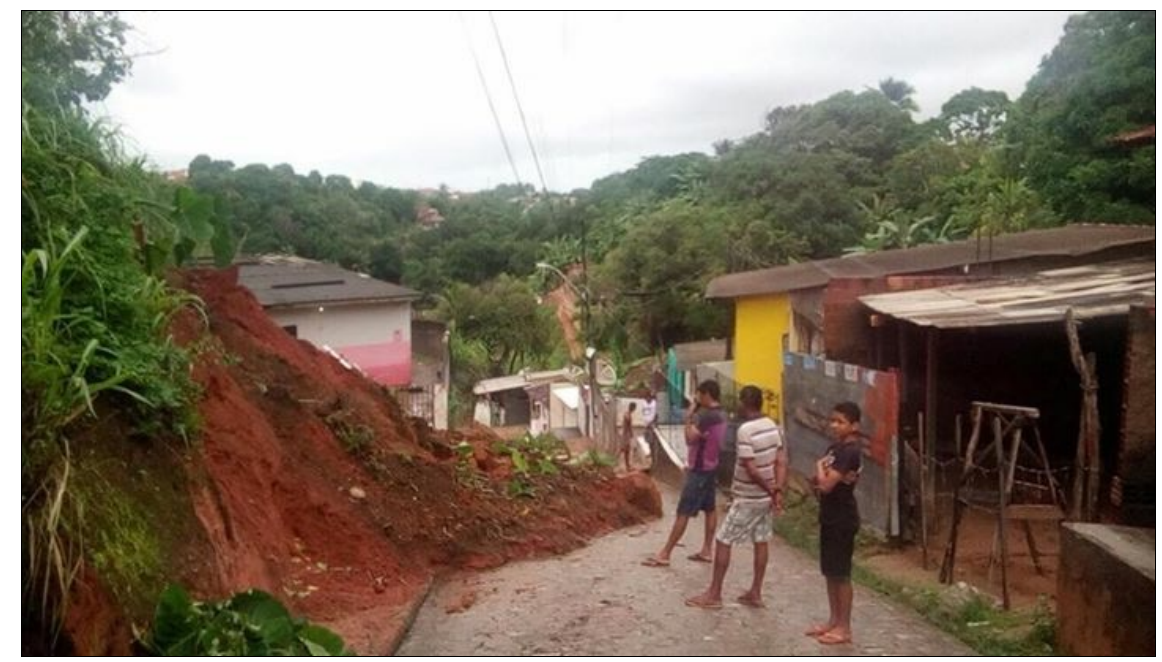

Figura 1: Deslizamento de terra (complexo Benedito Bentes). [[Q4: Q4]]

Fonte: autores. 
Desta forma, este trabalho apresenta uma avaliação dos limiares de precipitação que podem gerar deslizamentos de terra para a cidade de Maceió, abordando a relação entre precipitação e registros de ocorrências de deslizamentos de terra em áreas com características não homogêneas.

\section{RELAÇÃO ENTRE PRECIPITAÇÃO E OCORRÊNCIAS DE DESLIZAMENTOS DE TERRA}

A ocorrência de deslizamentos está diretamente relacionada com os eventos de chuva e o fator predominante pode variar de acordo com as características da área de risco. Por exemplo, um evento de chuva intensa em um curto período pode ser determinante na ativação de um deslizamento para uma área com um solo "A", enquanto que uma chuva de intensidade pequena a moderada, mas constante por um longo período, pode resultar em deslizamento de terra para uma área de solo "B".

Independente da intensidade e duração da chuva, certamente há uma relação entre a ocorrência de deslizamentos e os eventos de chuva. Santoro et al. (2010), por exemplo, mostram a relação entre a chuva acumulada e a chuva diária com a ocorrência de deslizamentos, indicando o limiar de ocorrência para o Estado de São Paulo (Figura 2). Conforme relatado por Parizzi et al. (2010), há diversos estudos regionais que apresentam relações semelhantes.

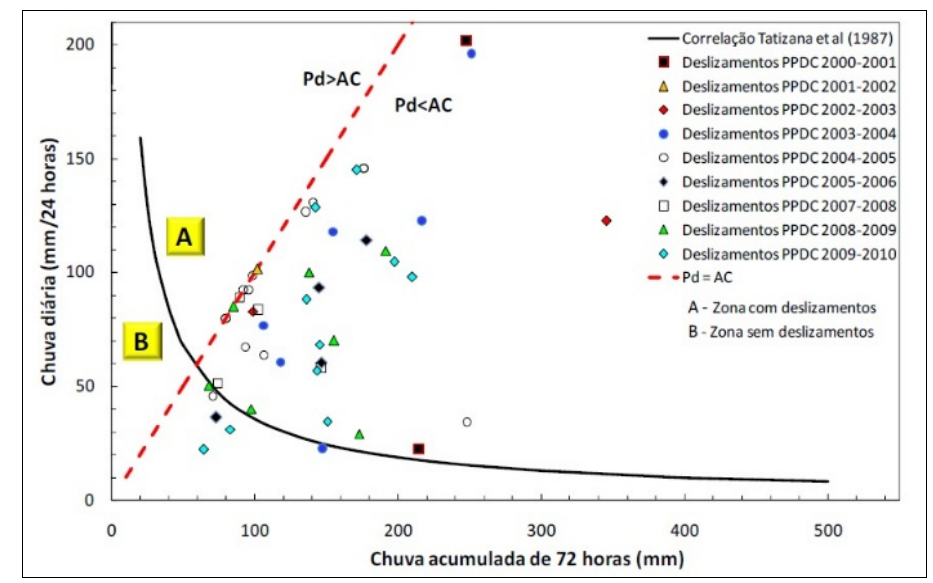

Figura 2: Correlação entre chuvas e deslizamentos. Fonte: Santoro et al. (2010)

Os estudos já realizados em zonas urbanas brasileiras, em sua maioria, apresentam, para cada região estudada, a curva de correlação entre precipitação diária (PD), precipitação acumulada (AC) de 72/84h, e a ocorrência de deslizamentos (figuras 3 e 4). Grande parte dos estudos, tem como referência a curva criada por Tatizana et al. (1987a, 1987b), que relaciona a chuva acumulada de $24 \mathrm{~h}$ com as chuvas acumuladas de $72 \mathrm{~h}$ (figura 3). Regiões com características semelhantes de declividade de terreno e cobertura vegetal apresentam comportamento dos dados semelhantes às curvas de TATIZANA, como em Castro (2006), mostrado na Figura 4.

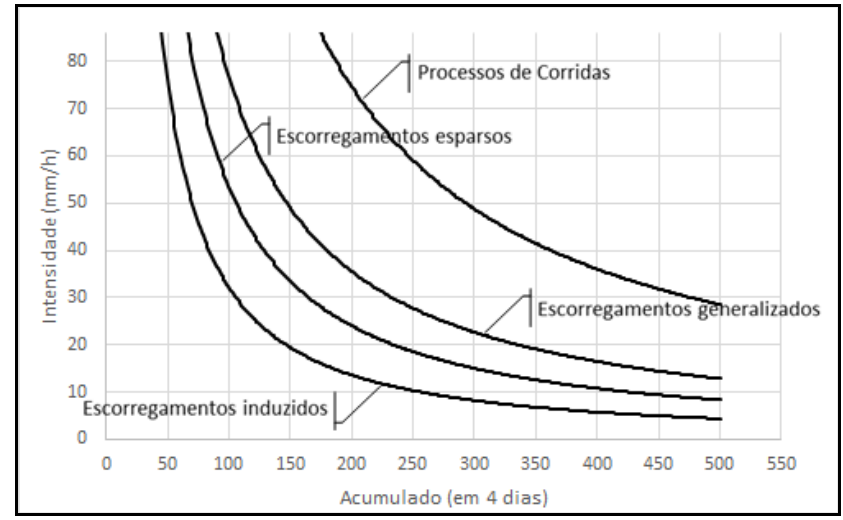

Figura 3: Correlação entre chuva e deslizamentos Fonte: (Tatizana et al., 1987a, 1987b) 


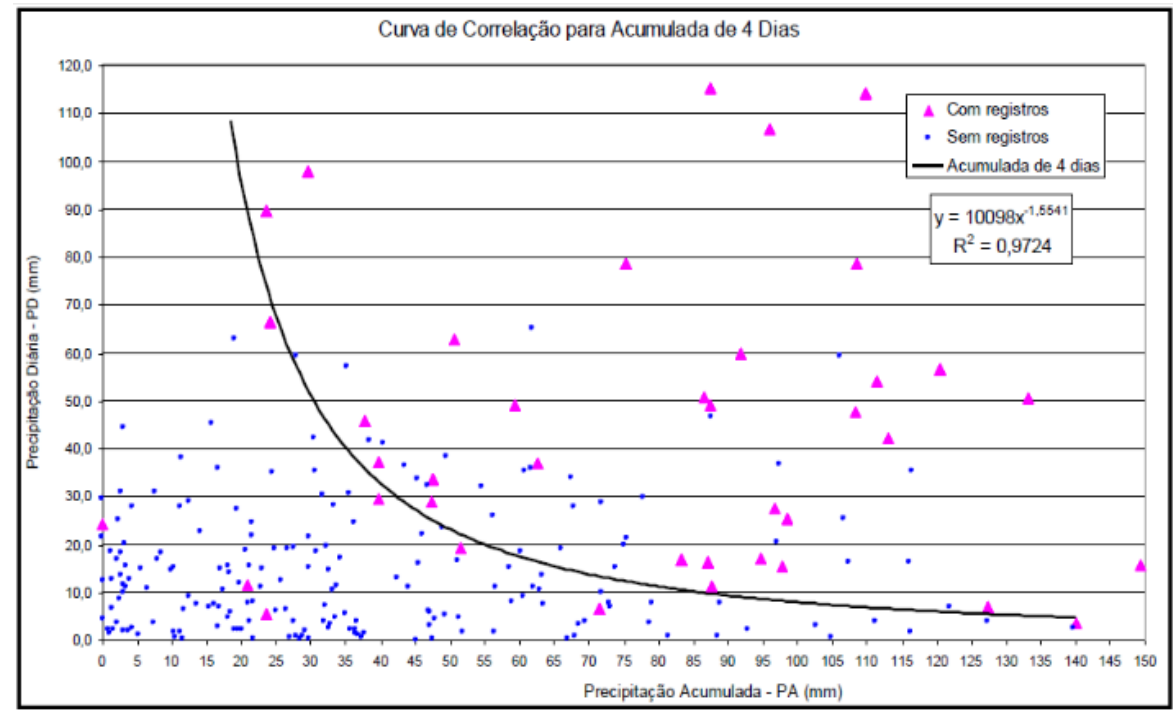

Figura 4: Curva de Correlação Fonte: Castro (2006)

Estudos desta natureza servem como referência para ações da Defesa Civil, na aplicação dos Planos de Prevenção de Defesa Civil (PPDC). Com a curva de correlação é possível identificar rapidamente as precipitações mínimas ocorridas que geraram deslizamentos em áreas de risco. Através de tais informações, as equipes de defesa civil fazem a aplicação do Plano de Emergência/Contingência (Maceió, 2017) e a emissão dos alertas necessários.

\section{MATERIAIS E MÉTODOS}

\section{Caracterização da área de estudo}

O município de Maceió está localizado no estado de Alagoas, com 509,55 km² de área de unidade territorial, e possui uma população de 1.029.019 habitantes (Instituto Brasileiro de Geografia e Estatística, 2018). A Região Metropolitana de Maceió está situada regionalmente na faixa sedimentar litorânea do Estado de Alagoas, fazendo parte da Bacia de Alagoas, Formação Barreiras, Sedimentos de Praia e Aluvião e Embasamento Cristalino (Agência Nacional de Águas, 2011). Registros de ocorrências de deslizamentos de terra e precipitações são realizados sistematicamente para os complexos de risco mapeados pela Defesa Civil da cidade de Maceió, indicados na Figura 5. 


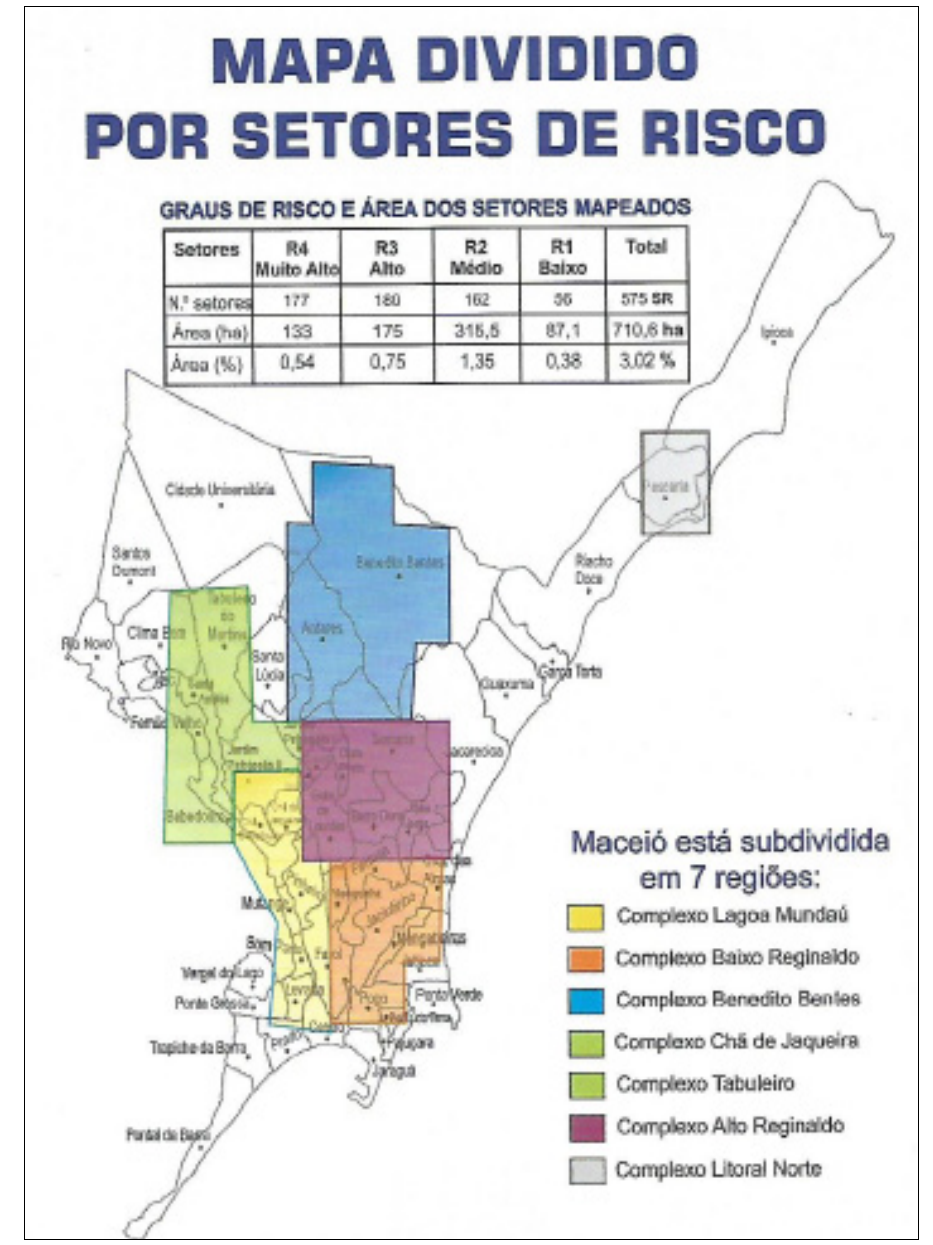

Figura 5: Mapa dos setores de risco Fonte: Maceió (2017)

As ocorrências de deslizamentos de terra noticiados e registrados na cidade de Maceió durante a quadra chuvosa do município (Abril a Julho), evidenciam a ligação direta entre precipitações e ocorrência de deslizamentos. 0 histórico dos eventos mostra o grande impacto que os deslizamentos de terra provocam no município, frequentemente com perda de vidas humanas, conforme relatado em GazetaWeb (2017).

Para este estudo, a Defesa Civil do município de Maceió, disponibilizou os registros de ocorrências para o período de 2015 a 2017. Nesse período, foram registradas 315 ocorrências.

\section{Obtenção e tratamento dos dados de deslizamentos de terra}

De acordo com Huang et al. (2015), o levantamento e o tratamento prévio das ocorrências e da precipitação são importantes para que os resultados sejam satisfatórios e confiáveis, principalmente na identificação dos deslizamentos que foram provocados pela precipitação ou por outras causas localizadas.

Para a realização deste trabalho, foram utilizados os registros de ocorrências de deslizamentos de terra que foram feitos pela defesa civil do município. Os registros são diários e dependem dos informes da população. A separação das ocorrências por complexo se deu basicamente pela localização da ocorrência de acordo com o mapa dos bairros de Maceió. A Figura 6 apresenta a distribuição percentual das ocorrências de deslizamentos de terra por complexo de risco, no período de janeiro de 2015 a agosto de 2017. 


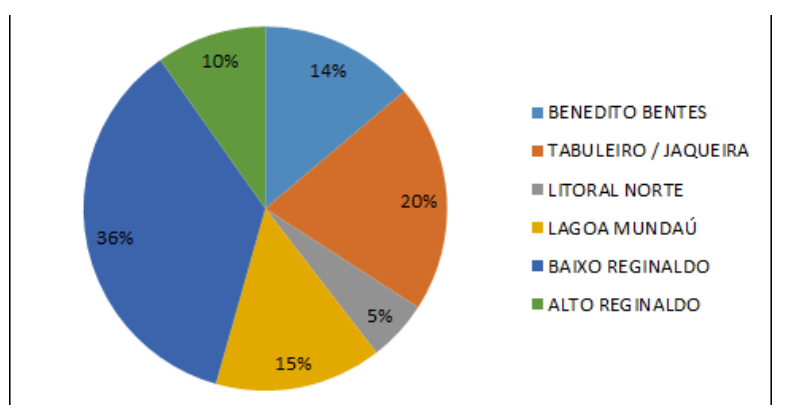

Figura 6: Percentual de ocorrências de deslizamentos de terra por Complexos de Riscos Fonte: Autores

\section{Obtenção e tratamento dos dados de chuva}

O Município de Maceió apresenta uma Normal Climatológica de precipitação anual de 2070,5 mm (Instituto Nacional de Meteorologia, 2018), distribuídos mensalmente conforme a Figura 7. Para a quadra chuvosa, que compreende o período de Abril a Julho, o acumulado esperado de chuvas é de $1256,6 \mathrm{~mm}$, o que corresponde a $61 \%$ da média anual.

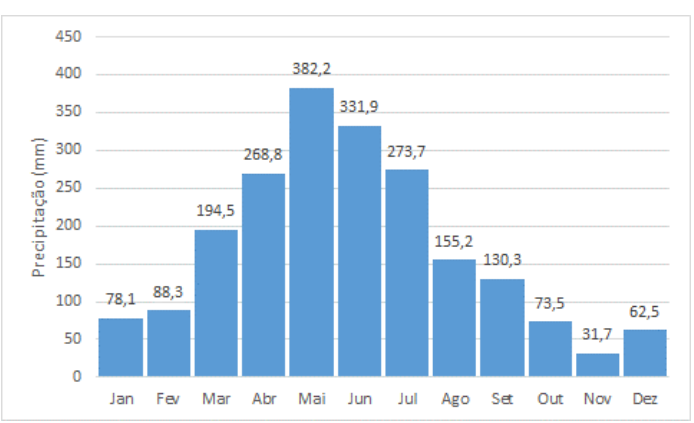

Figura 7: Normal Climatológica de Maceió

Fonte: INMET (Instituto Nacional de Meteorologia, 2018)

O período de informações disponíveis de ocorrências de deslizamentos de terra (de janeiro de 2015 a agosto de 2017) foi utilizado como referência para a análise dos dados de chuva. As informações pluviométricas utilizadas para este trabalho foram obtidas nos bancos de dados do CEMADEN (Centro Nacional de Monitoramento e Alerta de Desastres Naturais, 2018). As estações utilizadas para o trabalho estão apresentadas na tabela 1 .

Para obtenção das chuvas médias por complexo foi utilizado o método de Thiessen, onde foram consideradas as áreas de influência de cada pluviômetro em relação aos complexos de riscos.

Tabela 1: Estações pluviométricas em Maceió, relacionadas aos complexos de risco

\begin{tabular}{c|c}
\hline Estações & Complexo de risco de instalação \\
\hline $270430202 \mathrm{~A}$ & Tabuleiro do Martins2 \\
\hline $270430216 \mathrm{~A}$ & Cidade Universitária \\
\hline $270430205 \mathrm{~A}$ & Tabuleiro do Martins \\
\hline $270430217 \mathrm{~A}$ & Chã da Jaqueira \\
\hline $270430203 \mathrm{~A}$ & Farol \\
\hline $270430212 \mathrm{~A}$ & Cruz das Almas \\
\hline $270430207 \mathrm{~A}$ & Farol2 \\
\hline $270430209 \mathrm{~A}$ & Trapiche da Barra \\
\hline $270430218 \mathrm{~A}$ & Cambona \\
\hline $270430210 \mathrm{~A}$ & Benedito Bentes I \\
\hline $270430213 \mathrm{~A}$ & Antares \\
\hline $270430211 \mathrm{~A}$ & Ipioca \\
\hline $270430214 \mathrm{~A}$ & Ipioca
\end{tabular}

Fonte: CEMADEN (Centro Nacional de Monitoramento e Alerta de Desastres Naturais, 2018). 


\section{Definição dos Limiares de Precipitação que gera deslizamentos no município de Maceió}

Após a avaliação dos dados disponíveis para o trabalho (dados de chuvas e ocorrências de deslizamentos de terra), foram estabelecidos os gráficos de dispersão, afim de verificar a relação entre a precipitação acumulada para diferentes durações e o número de ocorrências de deslizamentos de terra. A precipitação foi analisada em relação à lâmina acumulada para diferentes durações, buscando identificar um padrão inicial que provoca deslizamento.

Para a determinação dos limiares de precipitação que desencadeiam deslizamentos, foram estabelecidos os acumulados de chuva diária para diferentes durações (1 dia a 15 dias), correlacionando-se com a ocorrência dos deslizamentos, com base na metodologia utilizada por Parizzi et al. (2010) e por Tatizana et al. (1987a, 1987b). Os autores citados avaliaram os cumulados de chuvas diárias de até 4 dias. Nesse trabalho, verificou-se a necessidade de avaliar os acumulados de até 15 dias, em função das características das precipitações e da ocorrência dos deslizamentos.

A observação dos padrões de ocorrências de deslizamentos mostrou não ser possível o estabelecimento das correlações apenas com base na média de dias acumulados de chuva, sendo necessário observar a lâmina acumulada para diferentes durações, identificando a duração mais relevante para cada caso. Essa observação pode ser feita através da dispersão entre acumulados de chuva e ocorrências. No estabelecimento das relações de acumulados de chuva (para diferentes durações) e de ocorrências, foram criados quadrantes para identificação dos limiares para cada análise realizada, considerando cada padrão de análise realizada.

\section{RESULTADOS E DISCUSSÃO}

\section{Relação entre ocorrência de deslizamentos de terra e a precipitação}

Conforme mostrado na Figura 8, pode-se verificar que existe uma relação entre o número de ocorrências de deslizamentos de terra e os diferentes períodos de chuva acumulada. Esta relação fica mais evidente quando os acumulados de chuva são maiores, indicando que, à medida que os acumulados de chuva aumentam, os registros de ocorrências também aumentam, mesmo considerando acumulados de chuva em 15 dias.

Nos gráficos apresentados, podemos ver a existência de grande número de ocorrências com pequena precipitação diária e poucas ocorrências com elevada precipitação diária, sugerindo que a intensidade da chuva não é o único fator determinante para os deslizamentos de terra.

Para o acumulado de 2 dias, observa-se o registro de várias ocorrências com acumulados de chuvas menores que $100 \mathrm{~mm}$, o que indica a necessidade de observar o acumulado em períodos mais longos (reafirmando o caráter regional desta análise). Os gráficos apresentados levam à conclusão de que alguns deslizamentos tiveram a intensidade da chuva como principal fator, mas que a consideração da saturação do solo para durações maiores deve ser também incorporada na análise das ocorrências. 

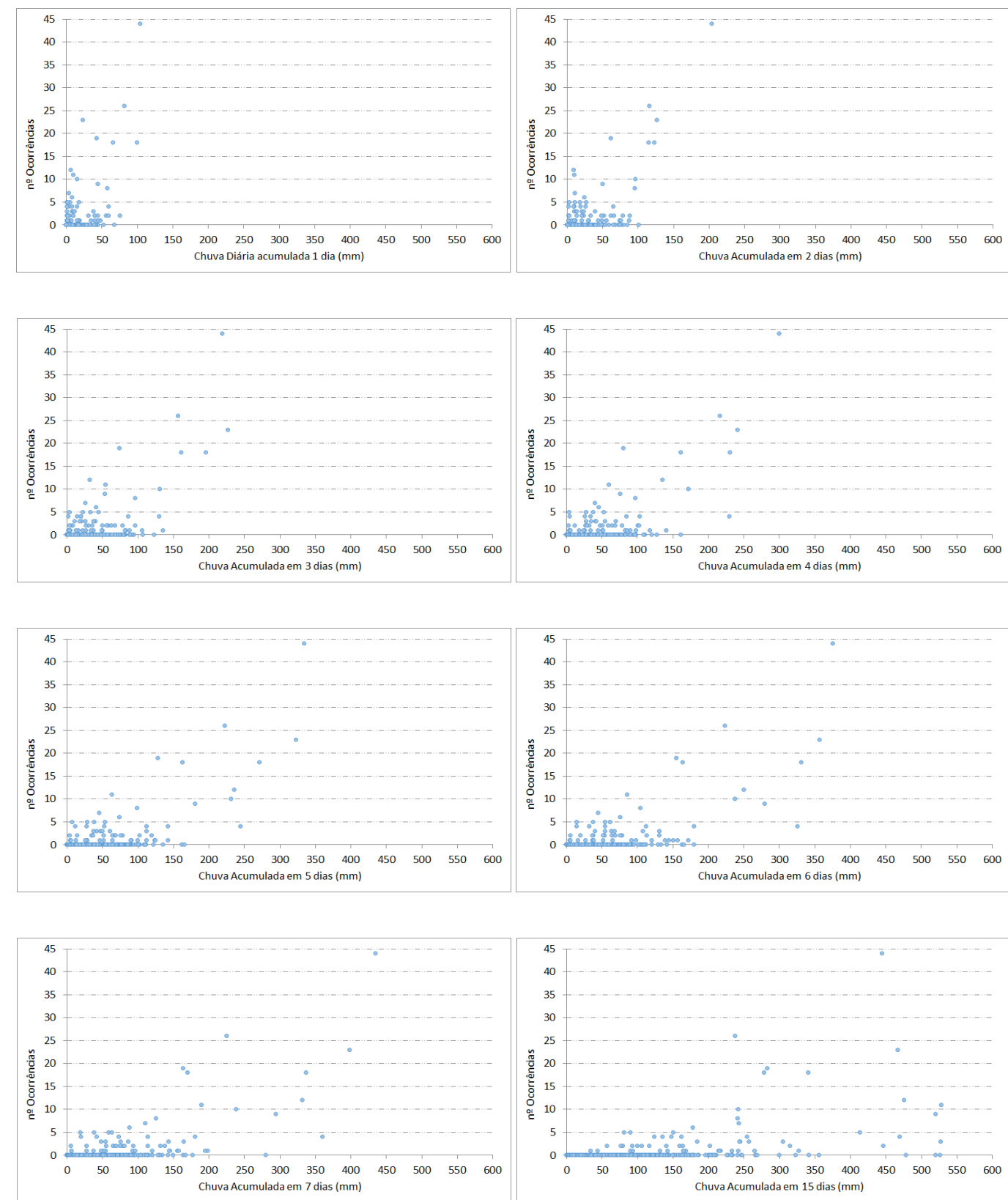

Figura 8: Relação entre o número de registros de ocorrências e acumulados de chuva Fonte: Autores

\section{Relação entre o acumulado de chuva e o acumulado de deslizamentos de terra}

Para identificar os fatores determinantes nos deslizamentos, buscou-se identificar a relação entre o acumulado de ocorrências e o acumulado de chuvas, conforme mostrado na Figura 9, entre 01 de janeiro de 2015 e 31 de agosto de 2017. 


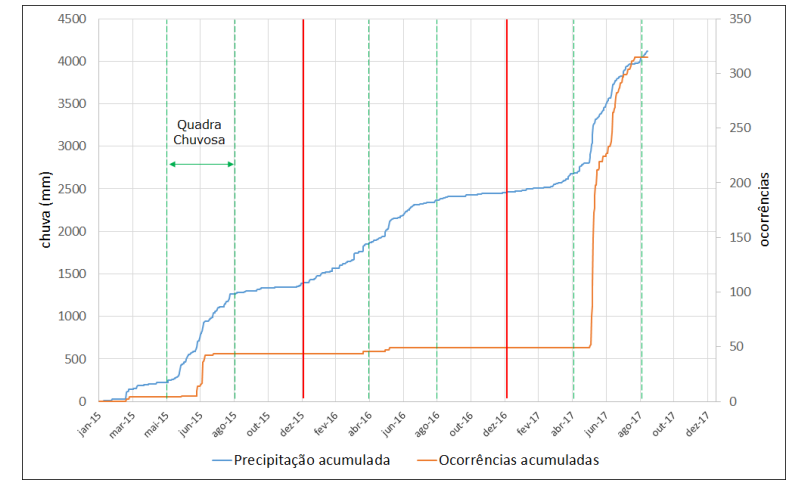

Figura 9: Acumulados de ocorrências de deslizamentos e chuvas entre 01/01/2015 e 31/08/2017 Fonte: Autor

Pode-se observar que a maior variação de ocorrências de deslizamentos registrados ocorre na quadra chuvosa, entre abril e julho, com maior incidência nos meses de maio e junho para o período analisado. Além disso, observa-se que o aumento brusco da inclinação da curva de precipitação acumulada aumenta a probabilidade de ocorrer um evento de deslizamento. Pode-se observar esses aumentos para os anos de 2015 e 2017, enquanto que para o ano de 2016, a curva de acumulado apresenta-se de uma forma mais constante, sem grandes variações. Isso fica evidenciado de forma mais clara quando observados os períodos chuvosos para cada ano em separado, com foco nos períodos onde a curva dos acumulados de chuva apresentou uma mudança mais brusca (figuras 10,11 e 12). Nos três anos avaliados, observou-se que há uma tendência positiva de aumento do número de ocorrências com o aumento do acumulado anual de precipitação (2016 foi o ano de menor volume de precipitação, com o menor número de ocorrências, com o oposto em 2017).

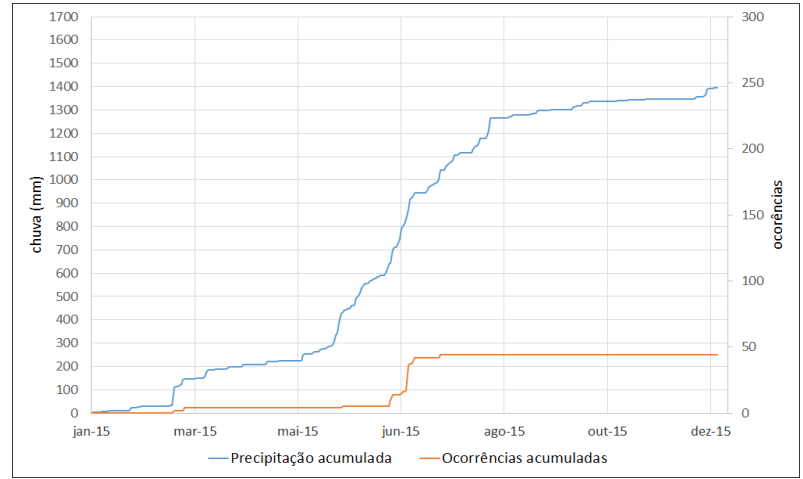

Figura 10: Acumulados de precipitação e ocorrências em 2015 (intervalo diário) Fonte: Autores

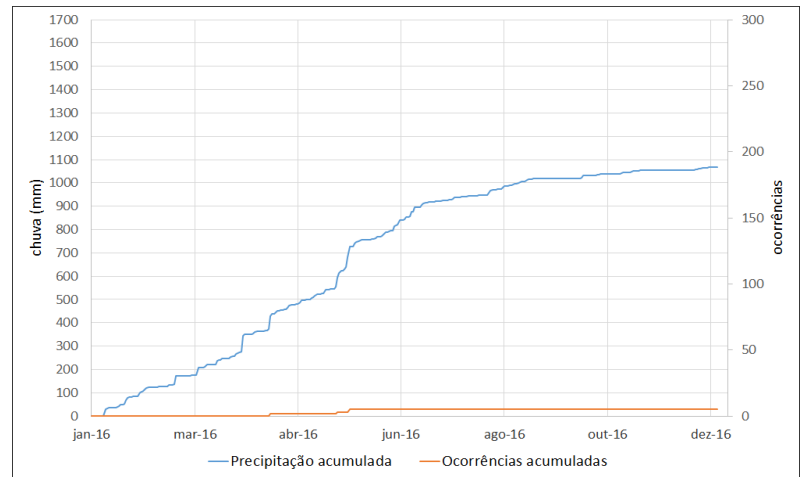

Figura 11: Acumulados de precipitação e ocorrências em 2016 (intervalo diário) Fonte: Autores 


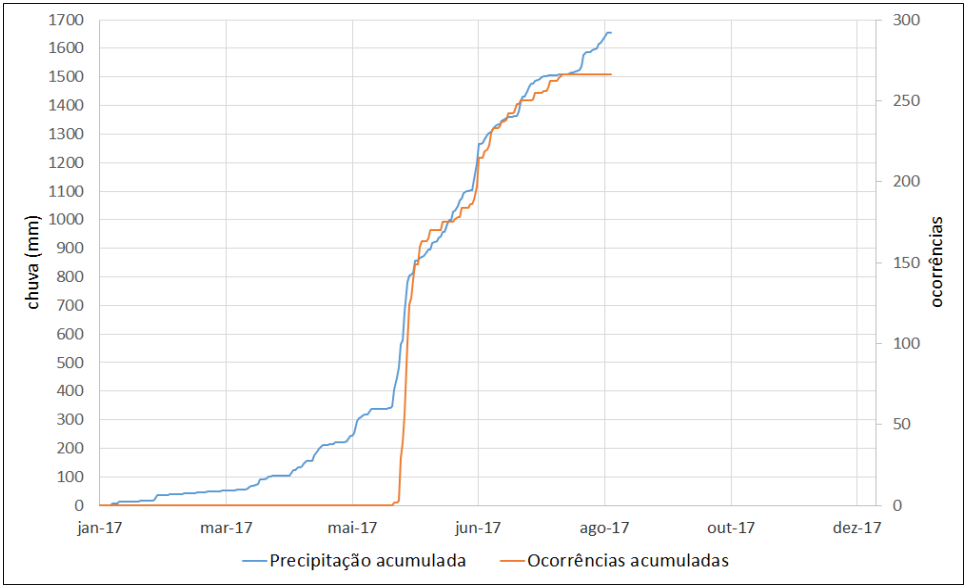

Figura 12: Acumulados de precipitação e ocorrências em 2017 (intervalo diário)

Fonte: Autores

Observando-se as figuras 13 e 14, verifica-se que para acumulados de chuva da ordem de 100 a $150 \mathrm{~mm}$, em períodos acumulados inferiores a 10 ou 5 dias, observa-se um grande número de ocorrências, indicando a relevância da avaliação dos acumulados de chuva para até 5 dias para a definição dos limiares de precipitação que podem gerar ocorrências de deslizamentos. Além dessa constatação, pode-se observar na figura 8d, que mesmo para acumulados de chuvas inferiores a $100 \mathrm{~mm}$ em 5 ou 10 dias ainda pode ocorrer um grande número de ocorrências de deslizamentos, o que sugere que a saturação do solo, com chuvas acumuladas em períodos maiores, também deve ser levada em consideração na definição dos limiares que podem gerar deslizamentos de terra na cidade de Maceió, pois mesmo após a passagem do período mais curto com chuvas mais intensas, o número de ocorrências continua a crescer.

Analisando-se as figuras 14 e 15, observa-se que a precipitação ocorrida entre os dias 21/05 e 27/05 potencializou o número de ocorrências de deslizamentos, considerando-se que o maior número de ocorrências teve início cerca de 7 dias após o início das chuvas, com um acumulado de cerca de $160 \mathrm{~mm}$. Observa-se, ainda, que nos meses de junho e julho a intensidade média (inclinação da curva de acumulado de chuva) foi menor, mas constante, com acumulado de cerca de $650 \mathrm{~mm}$ no período. Entre 28/06 a 30/06, houve intensificação da precipitação (150 mm em 3 dias), com aumento no número de ocorrências, potencializado pelo longo período de chuvas constantes que saturaram o solo.

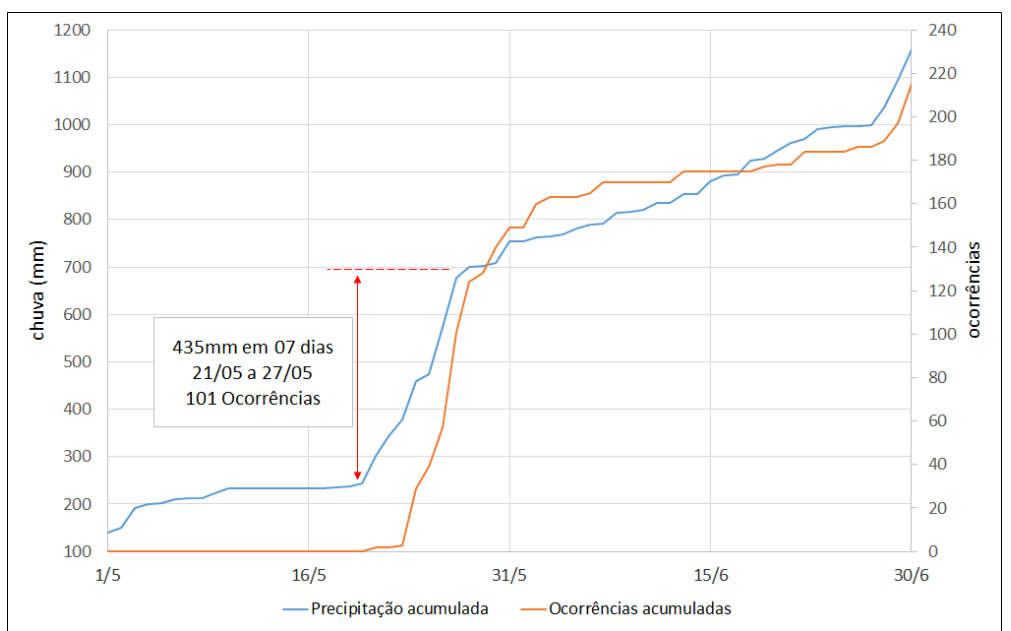

Figura 13: Acumulados de precipitação e ocorrências no evento mais extremo em 2017 Fonte: Autores 


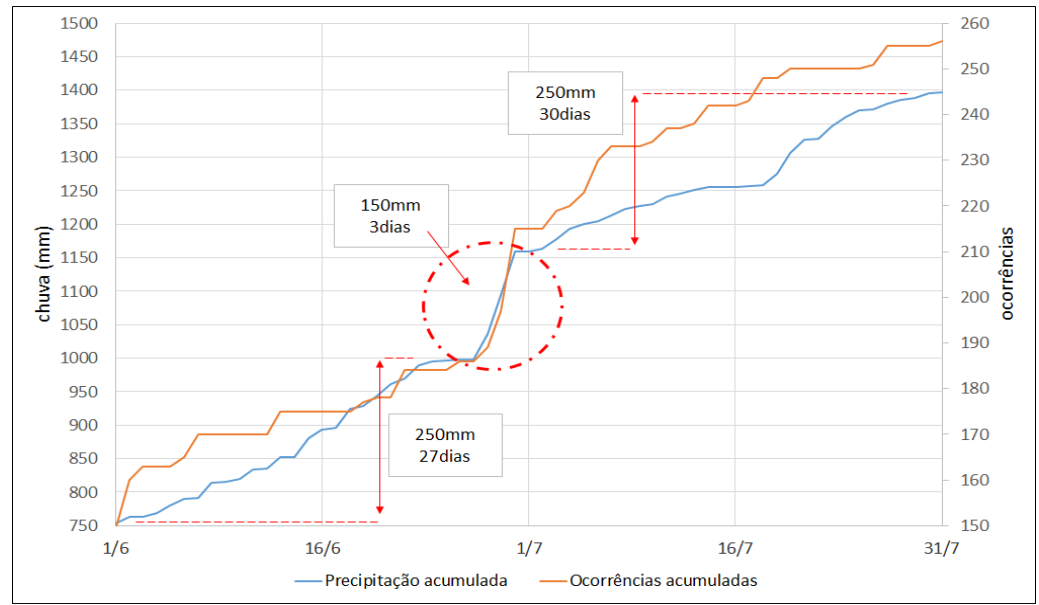

Figura 14: Acumulados de precipitação e ocorrências nos 60 dias de maior precipitação em 2017 Fonte: Autores

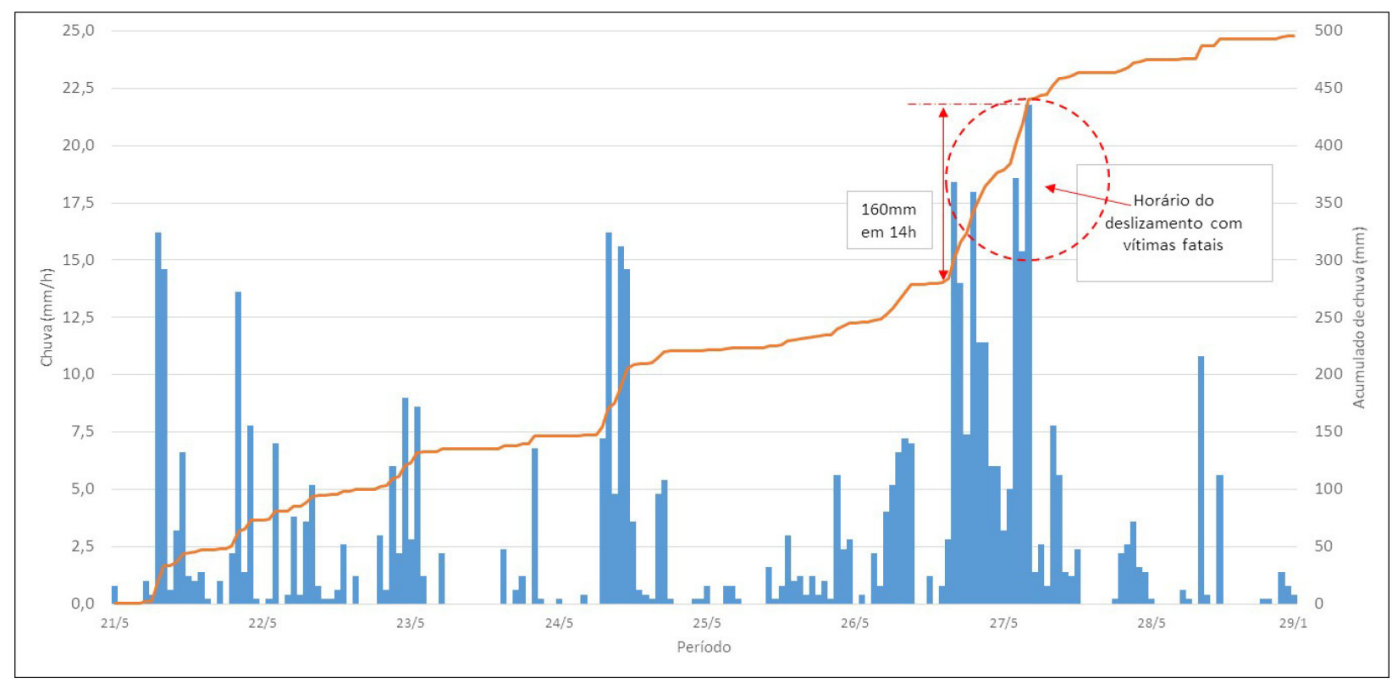

Figura 15 - Chuvas de 21 a 28/05/2017 que causaram 7 mortes na cidade de Maceió

Verifica-se, ainda, que o acumulado de 15 dias se manteve superior a $150 \mathrm{~mm}$ para todo o período de 60 dias (junho-julho de 2017), mesmo para os dias com baixa precipitação (abaixo de $40 \mathrm{~mm} / \mathrm{dia}$ ). Nesse caso, a precipitação ocorrida entre 28/06 e 30/06, além de contribuir para a manutenção da saturação do solo (desde o mês de maio), desencadeou a ocorrência de eventos nesse período. Nesse caso, com o solo saturado, qualquer precipitação um pouco mais intensa pode ocasionar deslizamentos de terra para as áreas de risco de Maceió.

\section{Análises da intensidade da precipitação que gera deslizamentos de terra}

De acordo com Huang et al. (2015), a definição do limiar de precipitação que gera deslizamentos deve considerar chuvas com intensidade mínima de $4 \mathrm{~mm} / \mathrm{h}$ e duração mínima de 6 h. Na figura 16, pode-se observar os eventos de chuva a partir de $24 \mathrm{~mm}$ que geraram ou não ocorrências de deslizamentos no período de 2015 a 2017, sem precipitação acumulada nos dias anteriores. 


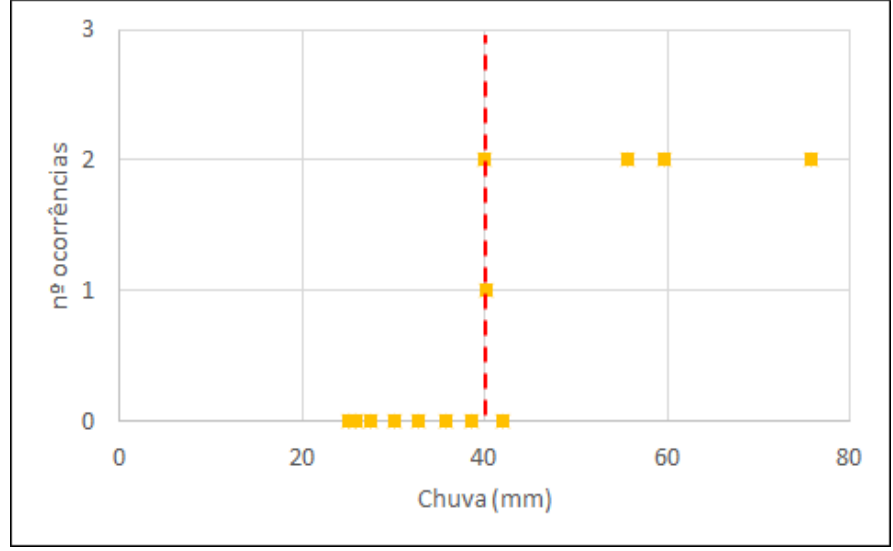

Figura 16: Ocorrências para chuvas maiores que $24 \mathrm{~mm}$ Fonte: Autores

Pode-se observar que, para chuvas diárias menores que $40 \mathrm{~mm}$, praticamente não foram registradas ocorrências. Por outro lado, para chuvas diárias maiores que $40 \mathrm{~mm}$ já se têm registros de deslizamentos, independentemente da precipitação em dias anteriores.

Esses resultados indicam que tanto eventos isolados (sem precipitação anterior) a partir de determinada intensidade quanto lâminas acumuladas de maior duração e menor intensidade contribuem para a ocorrência de deslizamentos. Desta forma, é prudente uma verificação das chuvas diárias de forma isolada, avaliando seus comportamentos horários durante o evento, afim de verificar quais durações são mais determinantes para desencadear deslizamentos de terra na cidade de Maceió.

Foram analisados eventos de chuva dentro e fora da quadra chuvosa que ocasionaram deslizamentos de terra. Estes eventos foram selecionados em alguns complexos para entender o comportamento médio para a cidade de Maceió.

Para ocorrências fora da quadra chuvosa, foram analisados 2 eventos de chuva em 18/02/2015, sendo um no complexo Chã-Tabuleiro e outro no complexo baixo Reginaldo. As estações pluviométricas mais próximas dos complexos registraram, respectivamente, 57,4 mm e 97,9 $\mathrm{mm}$. O comportamento das chuvas registradas para este dia são representados nas figuras $15 \mathrm{a}$ e $15 \mathrm{~b}$.

Os complexos apresentaram, para o dia analisado, eventos de chuva de $38,8 \mathrm{~mm}$ em $5 \mathrm{~h}$ (complexo chã-tabuleiro) e 87,8 mm em $8 \mathrm{~h}$ (complexo baixo-Reginaldo), calculadas pela média por polígonos de Thiessen considerando as estações disponíveis na área de influência. A intensidade dos médias nos complexos foi, respectivamente, $7,76 \mathrm{~mm} / \mathrm{h}$ e 10,98 mm/h (Tabela 2). Desta forma, pode-se constatar que eventos com duração superior a $5 \mathrm{~h}$ já podem provocar, isoladamente, deslizamentos de terra, dependendo da intensidade média da chuva.

Tabela 2: Intensidade média da chuva (mm/h) para os eventos do dia 18/02/2015

\begin{tabular}{|c|c|c|c|c|}
\hline Complexo & $\begin{array}{l}\text { Total acumulado } \\
\text { do evento (mm) }\end{array}$ & Duração (h) & $\begin{array}{c}\text { Intensidade } \\
(\mathrm{mm} / \mathrm{h})\end{array}$ & Ocorrências \\
\hline Chã-Tabuleiro & 38,80 & 5,00 & 7,76 & 1 \\
\hline Baixo Reginaldo & 87,80 & 8,00 & 10,98 & 1 \\
\hline
\end{tabular}

No caso dos eventos que geraram ocorrências na quadra chuvosa, foram avaliados os eventos do dia 24/05/2017, onde foram registradas 5 ocorrências no complexo Benedito Bentes, 7 ocorrências no complexo chã-tabuleiro, 3 ocorrências no complexo litoral norte, 2 ocorrências no complexo lagoa Mundaú, 5 ocorrências no complexo baixo Reginaldo e 1 ocorrência no complexo alto Reginaldo. As chuvas para esses complexos estão apresentadas nas figuras $17 \mathrm{c}$ a $17 \mathrm{~h}$. Os complexos apresentaram, para o dia 24/05/2017, eventos de chuva com durações variadas com períodos de $5 \mathrm{~h}$ a $9 \mathrm{~h}$, cujas intensidades estão apresentadas na Tabela 3. 
Tabela 3: Intensidade média da chuva (mm/h) para os eventos do dia 24/05/2017

\begin{tabular}{l|c|c|c|c}
\hline \multicolumn{1}{c|}{ Complexo } & $\begin{array}{c}\text { Total acumulado } \\
\text { do evento }(\mathbf{m m})\end{array}$ & Duração (h) & $\begin{array}{c}\text { Intensidade } \\
\text { (mm/h) }\end{array}$ & Ocorrências \\
\hline Benedito Bentes & 89,92 & 800 & 11,24 & 5 \\
\hline Chã-Tabuleiro & 66,60 & 7,00 & 9,51 & 7 \\
\hline Litoral Norte & 43,97 & 5,00 & 8,79 & 3 \\
\hline Lagoa Mundaú & 32,07 & 5,00 & 6,41 & 5 \\
\hline Baixo Reginaldo & 54,32 & 6,00 & 9,05 & 1 \\
\hline Alto Reginaldo & 60,17 & 6,00 & 10,03 & \\
\hline
\end{tabular}

Fonte: Elaborado pelos autores
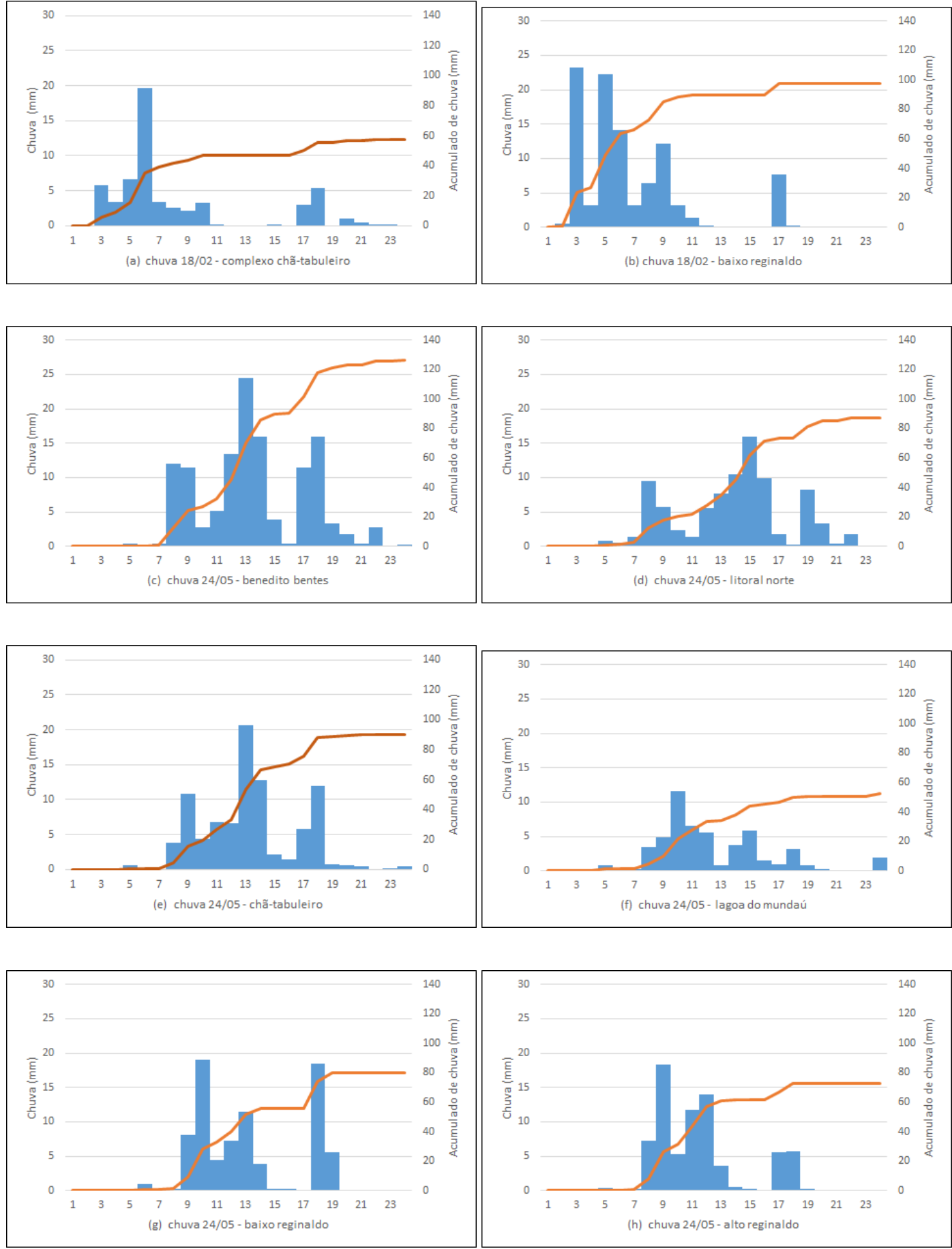

Figura 17: Chuva horária nos complexos de risco analisados Fonte: Autores 
Ao avaliar o conjunto de eventos de chuvas diárias dos eventos de 18/02/2015 (Tabela 2) e de 24/05/2017 (Tabela 3), pode-se verificar que a intensidade das precipitações que geraram ocorrências, tanto na quadra chuvosa quanto fora dela, apresenta mesma ordem de grandeza. Pode-se verificar também que para eventos com duração de 5 h já se tem registros de ocorrências, independentemente de estar ou não na quadra chuvosa.

Desta forma, entende-se que para a cidade de Maceió, chuvas com duração superior a 5 h e lâmina precipitada superior a $40 \mathrm{~mm}$ já são suficientes para gerar de deslizamentos de terra nos complexos de risco de Maceió. Sendo assim, podem existir ocorrências para qualquer período do ano, dependendo das características dos eventos de precipitações.

Os resultados indicam que o estudo de limiares de precipitação que geram deslizamentos não deve levar em consideração apenas a relação do acumulado de chuvas e as chuvas diárias, uma vez que eventos isolados podem gerar deslizamentos, dependendo da intensidade e do acumulado no evento, mas também dias seguidos de precipitação de baixa intensidade potencializam a sua ocorrência.

Desta forma, como cada região geográfica apresenta características peculiares de clima, solo, tempo, ocupação, não cabe uma regra geral para a avaliação dos eventos de chuva que podem gerar ocorrências, tornando-se necessária a investigação das características de cada região.

\section{Relação entre o acumulado de chuva e grupos de ocorrências}

As análises já apresentadas, mostraram que tanto as chuvas diárias quanto os acumulados de dias consecutivos são fatores que estão diretamente ligados aos registros de ocorrências. A Figura 18 apresenta uma análise para avaliar desde o mínimo de chuva que gera deslizamento de terra até o momento em que se tem uma instabilidade na região, considerando:

- $\quad$ Grupo 1 - Chuvas sem ocorrências

- Grupo 2 - Chuvas com registros de 1 a 5 ocorrências

- Grupo 3 - Chuvas com registros de 6 a 15 ocorrências

- Grupo 4-Chuvas com registros acima de 15 ocorrências 

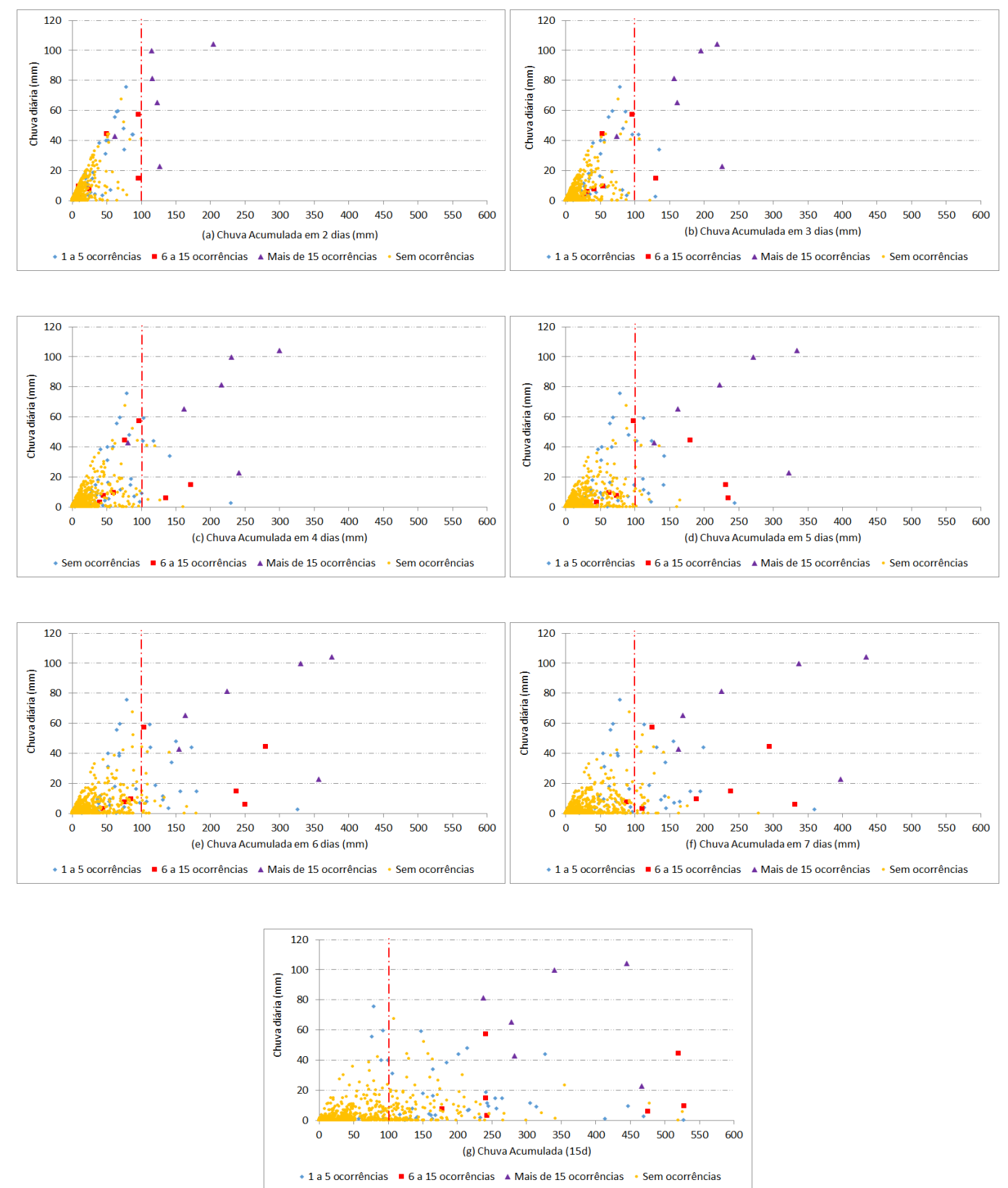

Figura 18. Precipitação acumulada por grupos de ocorrências Fonte: Autores

Avaliando-se a evolução dos acumulados de chuvas e as ocorrências registradas, verifica-se que os maiores números de ocorrências acontecem em períodos em que se tem acumulados de chuvas superiores a $100 \mathrm{~mm}$ para 15 dias. A situação fica mais evidenciada se considerarmos apenas os dados de chuvas com registro de ocorrências.

Pode-se verificar que para acumulados menores de chuva em longo período, as precipitações diárias são mais determinantes para o registro de ocorrências. Por outro lado, para maiores acumulados de chuva em longo período, a precipitação acumulada em todo o período parece ser mais determinante a ocorrência de maior número de deslizamentos.

\section{Limiares de Precipitação para Maceió}

Os limiares apresentados a seguir não são referenciados por equações de relação entre as variáveis precipitação e ocorrências, mas sim pelas análises que foram apresentadas quanto às características das chuvas em relação aos registros de ocorrências na cidade. 
Diante do exposto, entende-se que a melhor forma de apresentar os limiares para este trabalho, diante das informações disponíveis, é avaliar o acumulado de chuvas de acordo com a situação para cada caso. Quando não houver chuva anterior com acumulado significativo, avalia-se apenas a chuva diária para entender em que nível de atenção deve-se estar.

\section{Limiar de Chuva para precipitações diárias, com tempo seco antecedente}

Os resultados apresentados mostram que $40 \mathrm{~mm}$ de precipitação diária é o mínimo necessário para o surgimento de registros de ocorrências de deslizamentos, quando estas precipitações, independente de acumulados de chuvas anteriores, tiverem durações superiores a $5 \mathrm{~h}$. Sendo assim, sugere-se o limiar de $40 \mathrm{~mm}$ de precipitação diária com duração de 5 h como referência para estado de atenção para deslizamentos na cidade de Maceió.

\section{Limiar de chuva para acumulados de precipitação em dias consecutivos}

Fazendo a verificação da precipitação acumulada de 2 dias, 3 dias, 4 dias, 5 dias, 6 dias, 7 dias e 15 dias (Figuras 16a a 16g), chega-se à conclusão de que, à medida que a lâmina precipitada acumulada aumenta, as ocorrências também aumentam em proporção. Para todos as durações de acumulados estudadas, a partir de $100 \mathrm{~mm}$ o limiar de $40 \mathrm{~mm}$ por dia previsto para gerar início de situação de risco, torna-se cada vez menor, derrubando a barreira dos $40 \mathrm{~mm}$ já para o gráfico acumulado de $2 \mathrm{~d}$ (figura 16a).

Para acumulados de chuva a partir de $100 \mathrm{~mm}$, aparentemente, há uma certa instabilidade do solo, fazendo com que pequenas lâminas precipitadas (menores que $24 \mathrm{~mm}$ ) causem deslizamentos de terra na cidade de Maceió.

Sabendo-se que a partir de acumulados $100 \mathrm{~mm}$ no período de 15 dias, pode-se ter um deslizamento a qualquer momento, podemos trabalhar com esses dados, de acordo com os grupos classificados de ocorrências para entender melhor o comportamento das ocorrências em função das chuvas. Desta forma, a precipitação acumulada de 15 dias foi dividida em quadrantes, conforme mostrado nas figuras 19 e 20.

Para o quadrante A, pode-se perceber a influência das chuvas diárias, a partir do limiar de $40 \mathrm{~mm}$. Este limiar independe, conforme já discutido, do período de ocorrência do evento (dentro ou fora da quadra chuvosa).

No quadrante B, observa-se que, para acumulados de chuvas de 15 dias menores que $100 \mathrm{~mm}$ e chuvas diárias menores que $40 \mathrm{~mm}$, a chance de se registrar um deslizamento de terra na cidade de Maceió é praticamente nula. No entanto, conforme analisado para as chuvas acumuladas, se este acumulado se der em poucos dias anteriores, gerando picos de precipitação, pode-se estar diante de uma situação de solo instável. Desta forma, cabe verificar também se o período que está sendo avaliado é chuvoso ou não.

O quadrante $\mathrm{C}$ apresenta a situação mais desfavorável, onde estão combinadas chuvas diárias significativas com acumulados de chuvas em 15 dias maiores que $100 \mathrm{~mm}$. Para estas condições, é praticamente inevitável a ocorrência de deslizamentos de terra.

Na região D, pode-se perceber a grande influência dos acumulados de chuvas em longa duração, pois para acumulados maiores que $100 \mathrm{~mm}$, apesar de não ocorrerem chuvas diárias significativas, há instabilidade no solo, ocorrendo também grande possiblidade de serem registrados deslizamentos de terra. A partir de $200 \mathrm{~mm}$ de chuva acumulada em 15dias, o número de ocorrências é bastante elevado.

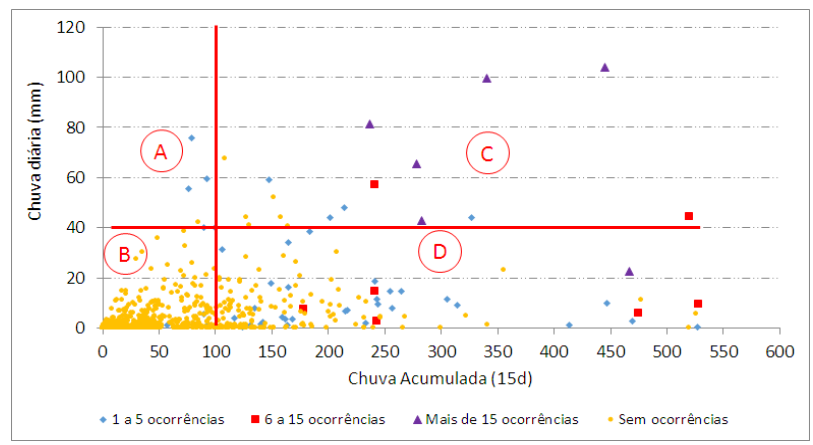

Figura 19: Quadrantes com todas as chuvas registradas no período de análise Fonte: Autores 


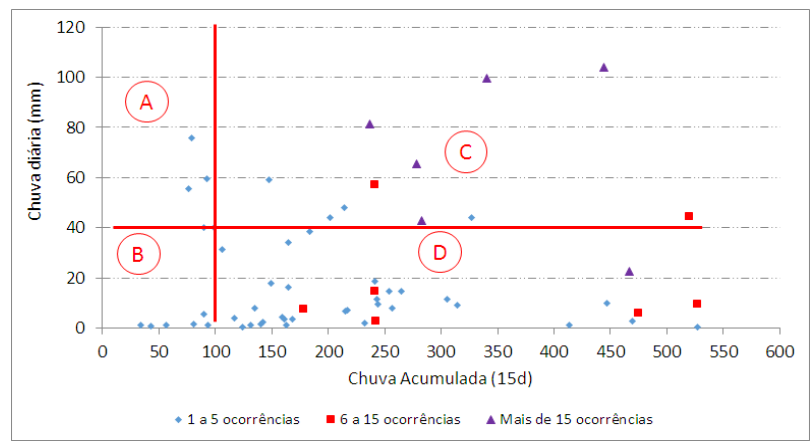

Figura 20: Quadrantes com chuvas que registraram deslizamentos no período de análise Fonte: Autores

\section{CONCLUSÃO}

A quadra chuvosa em Maceió ocorre no período de Abril a Julho, período de maior atenção para a Defesa Civil. Entretanto, observou-se que pode haver ocorrência de deslizamentos de terra fora deste período, dependendo das características da precipitação.

Os resultados apresentados indicam limiares de precipitação que geram deslizamentos agrupados em três grupos:

1) $40 \mathrm{~mm}$ de precipitação diária, distribuída em duração superior a $5 \mathrm{~h}$, em períodos sem chuva antecedente significativa (normalmente fora da quadra chuvosa);

2) $24 \mathrm{~mm}$ de precipitação diária quando o acumulado de precipitação em 15 dias for superior a $100 \mathrm{~mm}$;

3) $200 \mathrm{~mm}$ de precipitação acumulada em 15 dias.

Outros fatores como as características de solo e topografia não foram avaliados, por considerar que a própria definição das áreas de risco no município já agrupa, nos complexos de risco, as características relevantes para essa ocorrência.

Por fim, sugere-se que a defesa civil melhore o detalhamento das ocorrências com informações tais como referências locais e horário. Essas informações facilitarão o tratamento dos dados de ocorrências e possibilitarão a definição de limiares de precipitações para complexo de risco, de forma individual.

O presente trabalho, após análise dos resultados e sugestão dos limiares para cidade de Maceió, evidencia ainda, que independente da área em que for realizado os estudos dos limiares de precipitações, deve-se avaliar as informações de precipitações diárias e acumuladas para períodos de chuvas acumulados de acordo com o comportamento dos dados, e não com um período pré-determinado, pois as informações variam de região para região, mesmo que estas regiões sejam próximas. Desta forma, entende-se que não cabe uma regra geral para obtenção desses limiares, e sim um estudo das características das ocorrências em função das características das chuvas.

\section{REFERÊNCIAS BIBLIOGRÁFICAS}

Agência Nacional de Águas - ANA. (2011). Estudos hidrogeológicos para subsidiar a gestão sustentável dos recursos hídricos subterrâneos na região metropolitana de Maceió. Recuperado em 8 de janeiro de 2018, de http://www3.ana.gov.br/

Brasil. (1979). Lei no. 6.766 de 19 de dezembro de 1979. Dispõe sobre o Parcelamento do Solo Urbano e dá outras Providências.

Brasil. (2012a). Lei no. 12.608 de 10 de abril de 2012. Institui a Política Nacional de Proteção e Defesa Civil.

Brasil. (2012b). Lei no. 12.651 de 25 de maio de 2012. Código Florestal Brasileiro - Dispõe sobre a proteção da vegetação nativa.

Brasil. Ministério da Integração Nacional. (2013). Atlas de desastres naturais do Brasil - volume Alagoas 2013. Recuperado em 15 de janeiro de 2018, de http://www.integracao.gov.br/web/guest/defesacivil/publicacoes

Brasil. Ministério da Integração Nacional. (2018). Anuário brasileiro de desastres naturais. Recuperado em 10 de janeiro de 2018, de http://www.integracao.gov.br/web/guest/defesacivil/publicacoes 
Castro, J. M. G. (2006). Pluviosidade e Momentos de massa nas encostas de Ouro Preto (Dissertação de mestrado). Programa de Pós-graduação em Engenharia Civil - Geotecnia, Universidade Federal de Ouro Preto, Ouro Preto.

Centro Nacional de Monitoramento e Alerta de Desastres Naturais - CEMADEN. (2018). Recuperado em 10 de janeiro de 2018, de www.cemaden.gov.br

GazetaWeb. (2017). Chuvas em Maceió deixam dois mortos, desaparecidos e mais de cinco feridos. Recuperado em 27 de maio de 2018, de www.gazetaweb.globo.com

Huang, J., Ju, N. P., Liao, Y. J., \& Liu, D. D. (2015). Determination of rainfall thresholds for shallow landslides by a probabilistic and empirical method. Natural Hazards and Earth System Sciences, 15, 2715-2723. http://dx.doi.org/10.5194/nhess-15-2715-2015

Instituto Brasileiro de Geografia e Estatística - IBGE. (2018). Consulta de área, população e dados básicos dos municípios. Recuperado em 9 de janeiro de 2018, de https://www.ibge.gov.br

Instituto Nacional de Meteorologia - INMET. (2018). Normais climatológicas do Brasil 1961-1990. Recuperado em 10 de janeiro de 2018, de www.inmet.gov.br

Kobiyama, M., et al. (2015). Historical analyses of debris 1low disaster occurrences and of their scienti1ic investigation in Brazil. Labor \& Engenho, 9(4), 76-89.

Maceió. Prefeitura Municipal de Maceió. (2017). Plano de contingência. COMDEC.

Martins, F. T. (2014). Pluviometria crítica de escorregamentos na cidade do Rio de Janeiro: comparação entre períodos. Dissertação (Mestrado em Engenharia Civil). COOPE - UFRJ, Rio de Janeiro.

Mendes, R. M., Valerio Filho, M., Bertoldo, M. A., \& Silva, M. F. (2015). Estudos de Limiares Críticos Deflagradores de Deslizamentos no Município de São José dos Campos - SP (Brasil). Associação portuguesa de riscos, prevenção e segurança, imprensa da universidade de Coimbra. Territorium, 22, 119-129. http://dx.doi.org/10.14195/1647-7723_22_8

Michel, G. P. (2013). Modelagem de estabilidade de encostas com consideração do efeito da vegetação. (Dissertação de mestrado). Universidade Federal de Santa Catarina, Florianópolis.

Michel, G. P., Kobiyama, M., \& Goerl, F. B. (2014). Comparative analysis of SHALSTAB and SINMAP for landslide susceptibility mapping in the Cunha river basin, southern Brazil. Journal of Soils and Sediments, 14, 12661277. http://dx.doi.org/10.1007/s11368-014-0886-4

Michel, G. P., Goerl, R. F., \& Kobiyama, M. (2015). Critical rainfall to trigger landslides in Cunha River basin, southern Brazil. Natural Hazards, 75, 2369-2384. http://dx.doi.org/10.1007/s11069-014-1435-6.

Molina, E., Cardoso, A., \& Nogueira, F. (2015). Relação precipitação-deslizamento no Município de São Bernardo do Campo - SP. Ciência e Natura, 37, 46-54. http://dx.doi.org/10.5902/2179460X16214.

Parizzi, M. G., et al. (2010). Correlações entre chuvas e movimentos de massa no Município de Belo Horizonte MG. Artigos Científicos, Geografias, 6, 49-68. Recuperado em 5 de dezembro de 2019, de https://periodicos.ufmg.br/index.php/geografias/article/view/13296/10528

Ribeiro Neto, A. R., Batista, L. F. D. R., \& Coutinho, R. Q. (2016). Methodologies for generation of hazard indicator maps and flood prone areas: municipality of Ipojuca/PE. $R B R H, 21(2), 377-390$. http://dx.doi.org/10.21168/rbrh.v21n2.p377-390

Santoro, J., et al. (2010). Correlação entre chuvas e deslizamentos ocorridos durante a operação do plano preventivo de defesa civil em São Paulo. In 7o Simpósio Brasileiro de Cartografia Geotécnica e Geoambiental. São Paulo.

Tatizana, C., et al (1987a). Análise de correlação entre chuvas e escorregamentos, serra do mar, mun. de Cubatão. In 5o Congr. Bras. Geol. Eng. (pp. 225-236). São Paulo: ABGE.

Tatizana, C., et al (1987b). Modelamento numérico da análise de correlação entre chuvas e escorregamentos aplicado às encostas da serra do mar, município de Cubatão. In 50 Congr. Bras. Geol. Eng. (pp. 237-248). São Paulo: ABGE.

Tominaga, L. K., Santoro, J., \& Amaral, R. (2009). Desastres naturais. In: Escorregamentos, inundações e enchentes (pp. 25-37, 39-52). São Paulo.

UNISDR. (2015). Strategic framework 2016-2021 (pp. 4). Switzerland.

UNISDR. (2018). Disasters statistics 2005-2014. Recuperado em 8 de fevereiro de 2018, de www.unisdr.org/we/inform/disaster-statistics 
Zahiri, E. P., Bamba, I., Famien, A. M., Koffi, A. K., \& Ochou, A. D. (2016). Mesoscale extreme rainfall events in West Africa: the cases of Niamey (Niger) and the Upper Ouémé Valley (Benin). Weather and Climate Extremes, 13, 15-34. http://dx.doi.org/10.1016/j.wace.2016.05.001.

David de Lima Santos

CONTRIBUIÇÃo: realizou a pesquisa, levantamento e análise de dados, análise e discussão dos resultados e escrita do artigo.

Carlos Ruberto Fragoso Jr.

CONTRIBUIÇÃO: contribuiu na concepção do trabalho, análise de dados, discussão de resultados e escrita do artigo.

Vladimir Caramori Borges de Souza

CONTRIBUIÇÃO: supervisor da pesquisa e orientador do trabalho, contribuiu na concepção do trabalho, análise de dados, discussão de resultados e escrita do artigo. 